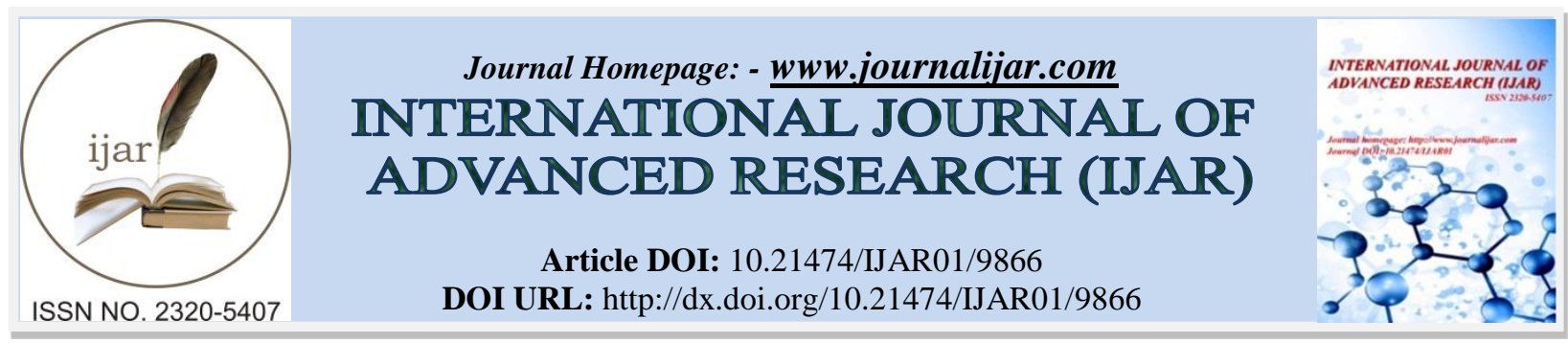

RESEARCH ARTICLE

\title{
IMPACT OF CLIMATE CHANGE ON RELIABILITY AND WATER SAVING POTENTIAL OF DOMESTIC RWH SYSTEMS IN DHAKA.
}

\author{
Asif Hossain. \\ Lecturer, Department of Civil Engineering, Ahsanullah University of Science and Technology.
}

\section{Manuscript Info}

Manuscript History

Received: 08 August 2019

Final Accepted: 10 September 2019

Published: October 2019

Key words:-

Gamba grass, accessions, yield, crude protein, mineral contents, Benin.

\section{Abstract}

As an alternative and sustainable source of water, rainwater harvesting (RWH) has been studied extensively around the world in recent times. Climate change may bring significant changes in rainfall pattern. In this study, 60 years historical rainfall was evaluated. Frequency analysis for rainfall events and dry day duration was carried out to produce exceedance probability curves. Notable change in rainfall pattern occurred for $10^{\text {th }}$ percentile exceedance probability for the decades 1976-1985, and 2006-2015, from $41 \mathrm{~mm}$ to $46 \mathrm{~mm}(+12.2 \%)$, and from $44.5 \mathrm{~mm}$ to $40.1 \mathrm{~mm}(-9.9 \%)$ respectively. Change in dry day duration was insignificant. A software was developed in MATLAB to simulate the daily water balance model for determining reliability, volumetric reliability and water saving potential of the RWH systems. Analysis showed highest reliability in the 1976-1985 decade at 8.2\%-3.4\%, gradually decreasing to lowest during 2006-2015 at 6.4\%-2.4\%, depending on catchment and water demand scenario. Volumetric reliability was highest at $15.5 \%-10 \%$ for the decade 1976-1985, gradually falling to $13 \%-8.5 \%$ at 2006-2015. For water saving potential, 1955-1964 was treated as baseline. 1976-1985 showed the highest increase in water savings potential at $(+11.5 \% \sim+11.9 \%)$, gradually decreasing to $(-4.5 \% \sim-5.1 \%)$ during 2006-2015. Changes for reliability and volumetric reliability are not major, but still noticeably reduced in the recent decade. Effect on water saving potential is more prominent possibly indicating significant negative impacts of climate change on RWH systems in Dhaka city.

Copy Right, IJAR, 2019,. All rights reserved.

\section{Introduction:-}

Water is the absolute most crucial component for survival of humans. It is impossible to run our day to day activities without the use of water in every sector. Sustaining any size of population requires available water sources with reasonable level of access. Depending on the use of water, the required quality of water would also vary. As the population around the globe is steadily increasing along with the industrial growth and other facilities required sustaining this population, it has started to put an immense strain on the renewable water sources of the world. While the major portion of the earth is covered with oceans, this water is not accessible to us except by the process of desalination, which usually tends to be expensive. As of present, vast majority of populations around the world are dependent on ground water and surface water sources. Unsustainable use of water has caused drastic water shortage scenarios in other parts of the world. Notable among these would be Cape Town, South Africa almost reaching "day 
zero", when the taps are turned but no water supply available for the people. The six dam reservoir system reached a record low of $13.5 \%$ of capacity. Another noteworthy incident of unsustainable water resource management occurred in the ecosystem collapse at the Aral Sea. Expansion of irrigation projects that were unsustainable in the water resource context, led to the 708 cubic meter Aral Sea shrinking to a meager 75 cubic meters by 2007, salinity levels rising from 14g/l to more than 100g/l (Micklin, 2008). In locations spanning from India \& China to United States and France, twenty one of thirty seven largest aquifers are being depleted, more water being removed than is replaced (Richey et al., 2015).

Thus, it has become imperative to implement alternate and sustainable sourcing of water supply. Among the alternative sources of water supply, RWH appears to be most promising. Extensive research has been carried out in many developed and developing countries regarding the feasibility and reliability of the technology. (Mati et al., 2006) has used GIS tools to show opportunities for RWH in selected countries of Africa such as Botswana, Malawi, Rwanda, Uganda, Zimbabwe among others. However, (Fisher-Jeffes, 2015) has also shown RWH in domestic context is only economically feasible for a minority of users when large catchment area is available and there is high demand at the same time.There has been a development in South Korea of revisiting RWH as an adaptation strategy to deal with climate extremes, focusing on highly developed urban area and large scale RWH implementations (Han and Mun, 2011).(Gould et al., 2014) outlined a project carried out in Gansu province in China, which led to installation of more than 2 million rainwater tanks with total capacity exceeding 73 million cubic meters up until year 2000. In Australia, (Burns et al., 2015) observed potable water savings in the range of 10-100\% from continuous monitoring RWH systems.Largest reductions were observed where RWH tank supplied for multiple indoor demand i.e. toilet flushing, cloth-washing and hot water usage. (Umapathi et al., 2012) carried out study with similar result across twenty households in Queensland. The potable water saving was found $31 \%$ on average across all the households in consideration.Countries such as Austria, Denmark, Belgium and Switzerland has seen a rise in popularity in implementing RWH, reportedly with potable water pricing being the main driver (Godskesen et al., 2013; Ringelstein, 2015).

Currently water supply system in Dhaka is majorly dependent on Groundwater. Currently 78 percent of water is supplied from underground sources and only 22 percent from surface water sources. Against a demand of 2450 MLD, DWASA (Dhaka Water Supply and Sewage Authority) is currently capable of producing 2500 MLD and therefore able to fulfill the demand. However, observation reveals that the demand is increasing rapidly, almost by 50 MLD every consecutive year in the recent years, and sometimes even more (DWASA, 2019). Groundwater level is declining at a rate of two to three meters in many places around Dhaka city (Khan, 2013). While DWSA intends to increase reliance of surface water, it poses certain challenges i.e. thorough and often expensive treatment necessary before supplying surface water to consumers. This necessitates exploring alternative sourcing of water supply - such as rainwater harvesting - on an urgent basis. As part of addressing the issue of increasing potable water demand, Bangladesh government has already amended the Building Construction Rules (2008)(Bashar et al., 2018). Newly proposed Bangladesh National Building Code explicitly lays out requirement for incorporation of rainwater harvesting system in newly constructed buildings (BNBC, 2015). Rajdhani Unnayan Kartripakkha, or RajUK literally the Capital Development Authority of the Government of Bangladeshhas proposed incorporating RWH on policy making level, specifically making it mandatory for high rise buildings (RajUK, 2015).

It is expected that implementation of RWH will reduce stress on existing water sources. However, efficiency and reliability of a RWH system depends on several factors - available catchment area, size of storage tank, water demand and most importantly, temporal distribution of available rainfall on site. While a study carried out (Karim et al., 2015) looked into economic feasibility and reliability of RWH systems under different climatic conditions, studies regarding the possible impact of climate change on feasibility and reliability of RWH systems remain scarce. Studies based on future climate model projections for different emission scenarios i.e. RCP 4.5(moderate emission scenario), RCP 8.5(extreme emission scenario) predict considerable variability of rainfall pattern of small magnitude in the near future (next few decades) and similar but of larger magnitude in the distant future (near the end of the century). It is also observed with very high confidence level $(\geq 90 \%)$ that intensity and frequency of extreme events will increase, monsoons will likely $(\geq 66 \%)$ lengthen in duration, and the difference of precipitation between dry regions and wet regions as well as dry seasons and wet seasons will considerably increase (Stocker, 2014).

As opposed to using projected climate model precipitation data for understanding climate change, this study will use 60 years historical data segmented into decadal rainfall data. The trend of change in rainfall event pattern and length and frequency of dry days will be evaluated to understand the impact of climate change on rainfall pattern in Dhaka 
so far. The decadal rainfall data will be used to evaluate the change of performance of RWH systems from decade to decade in terms of reliability and water saving efficiency of these systems.

\section{Methodology:-}

Study Area

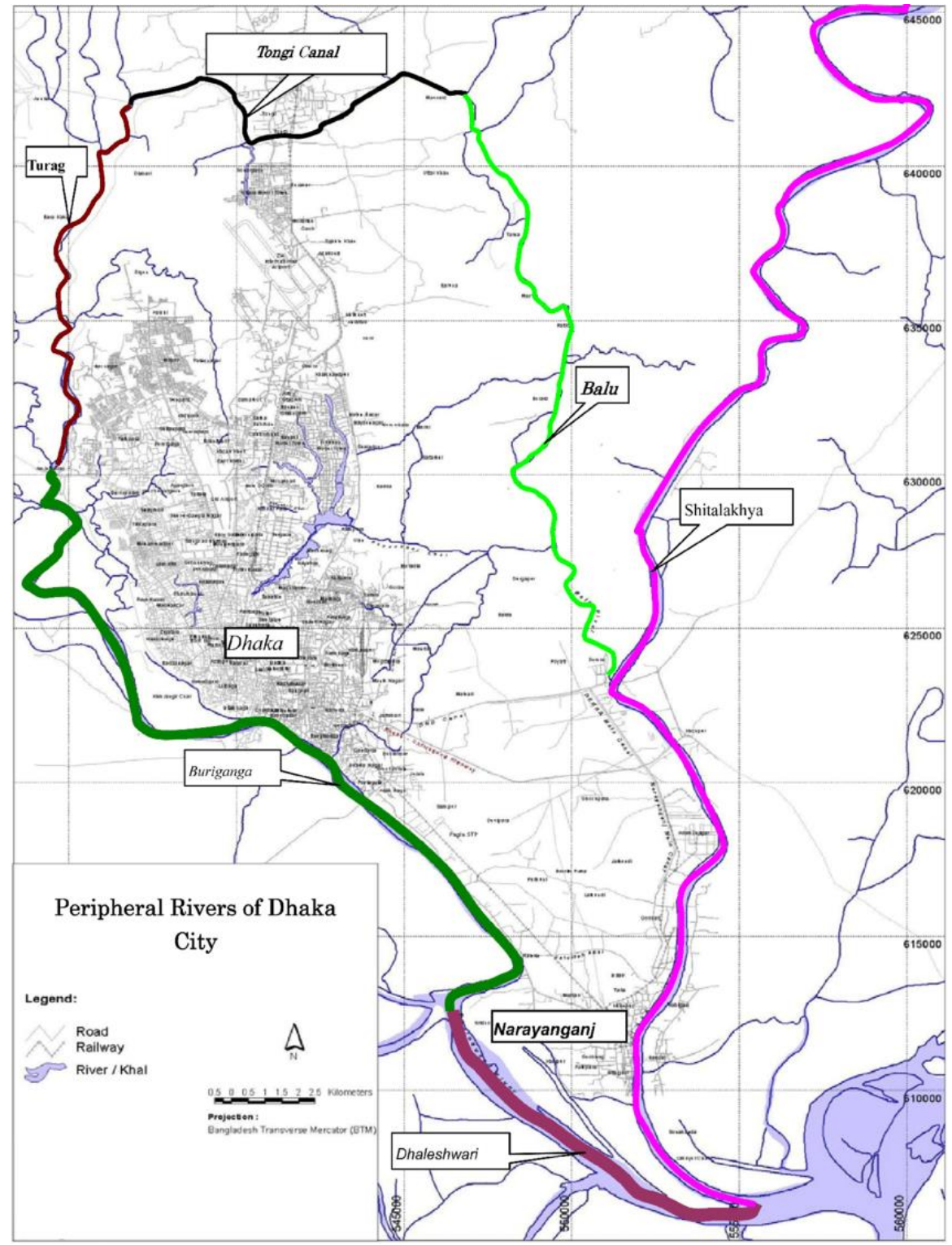

Figure 1:-Maps of peripheral rivers around Dhaka City, adopted from (Banu, 2013)

Dhaka, the capital of Bangladesh is situated at around latitude $23^{\circ} 42^{\prime}$ and longitude $90^{\circ} 23^{\prime}$. One of the major cities of South Asia, Dhaka is bounded by Turag and the Buriganga River on the western side, with river Dhaleshwari to the south and Tongi khal in the north, which connects both Turag and Balu rivers (Zaman, 2017).

The population of Dhaka alone is estimated to surpass 20 million by 2019, and expected to reach 28 million by 2030, should the current rate population growth continue (DeSA, 2019). The average annual precipitations for the six decades and number of wet days in Dhaka are given in table 1 for a rough idea about the volume of rainfall received by the city during the time period of study. 


\begin{tabular}{|l|l|l|}
\hline Decade & Average Annual Rainfall $(\mathrm{mm})$ & Average wet days per year \\
\hline $1955-1964$ & 1943 & 87.1 \\
\hline $1965-1975$ & 1973.1 & 116.1 \\
\hline $1976-1985$ & 2154.4 & 126.3 \\
\hline $1986-1995$ & 2102.8 & 120.1 \\
\hline $1996-2005$ & 2091.9 & 123.6 \\
\hline $2006-2015$ & 1844.1 & 123.6 \\
\hline
\end{tabular}

Table 1:-Average rainfall of Dhaka during the six decades studied considered in study and average wet days per year.

\section{Frequency Analysis}

To characterize the change in pattern of rainfall, frequency analysis was carried out for rainfall events and dry duration frequency and length in each decade as was done by (Alamdari et al., 2018). Available historical rainfall data was analyzed after processing all the data into a daily resolution. Continuous decadal rainfall data was sorted from largest to smallest, assigning rank $m$ to each event. For total rainfall events of number $n$, exceedance probability was calculated for each rainfall event using the equation:

$\mathrm{P}=(\mathrm{m} \times 100) /(\mathrm{n}+1)$

Probability of storm events in each decade was compared by plotting exceedance probability curves for each decade. For frequency analysis of dry duration, rainfall events below $2 \mathrm{~mm}$ were set as dry days. Previous studies conducted by (Guo and Baetz, 2007) and (Kus et al., 2010) have shown that $2 \mathrm{~mm}$ of first flush can significantly improve quality of rainwater collected. (Martinson and Thomas, 2005) showed that each $1 \mathrm{~mm}$ of rainfall diverted in first flush can roughly reduce $50 \%$ of remaining turbidity load from collected rainwater. Therefore, in the context of RWH systems, rainfall events below $2 \mathrm{~mm}$ were set as dry days. After the $2 \mathrm{~mm}$ threshold screening, dry day duration between consecutive rainfall events were calculated and these durations were sorted into similar ranks as rainfall events (from largest to smallest). According to rank, probability was assigned to each dry day event and probability curve for each decade was plotted for comparison.

\section{Simulation Model}

A simulation model was developed using MATLAB program to simulate daily water balance model used by notable researchers previously (Khastagir and Jayasuria, 2010; Rahman et al., 2012; Mehrabadi et al., 2013; Imteaz et al., 2014; Karim et al., 2015). Reliability, Volumetric reliability, Overflow ratio as percentage and Water Savings in KL was simulated and calculated on a daily scale as detailed in the following equations:

$\operatorname{Vol}(t)=\operatorname{Inf}(t)-\operatorname{DaCon}$

$\operatorname{Vol}(t)=0$, when $\operatorname{Vol}(t)<D a C o n$

$\operatorname{Vol}(t)=$ Cap, when $\operatorname{Vol}(t)>$ Cap

$r w U s g(t)=$ DaCon, when $I n f(t)+\operatorname{Vol}(t-1) \geq D a C o n$

$r w U s g(t)=\operatorname{Inf}(t)+\operatorname{Vol}(t-1)$, whenInf(t) $+\operatorname{Vol}(t-1)<\operatorname{DaCon}$

Where, $\operatorname{Vol}(t)$ is the accumulated rainwater in the storage tank on $t$ th day, $\operatorname{Inf}(t)$ is the inflow on the $t$ th day, DaCon is the daily water consumption, Cap is the storage tank capacity, and $r w U s g(t)$ is the volume of water consumed to meet the daily demands. Overflow ratio is the percentage of rainwater that was spilled during evaluation period due to lack of storage availability and is defined as:

Overflow ratio $=($ Sum of spilled rainwater due to storage tank overflow during evaluation period $\mathrm{x} 100) /$ Sum of inflow of rainwater during evaluation period

Reliability is defined as the percentage of days during evaluation period when the daily water demand was fully met using only collected rainwater. Volumetric Reliability is the percentage of total water demand that was met using rainwater alone.

Reliability $(\%)=\{($ total number of days evaluated - number of days with unmet demand $) \times 100\} /$ Total Number of days 
Volumetric reliability $(\%)=$ Volume of rainwater supplied during evaluation period/ Total water demand during evaluation

\section{Data}

Historical rainfall data for the period 1955-2015 was collected from Bangladesh Meteorological Department. Data for the year 1974 was not available. While World Meteorological Organization suggests using continuous precipitation data length of 30 years (WMO, 1989), (Geraldi and Ghisi, 2017) demonstrated that 10 year length of rainfall time series produces reasonably similar results to those of 30 years continuous series when evaluating the performance of RWH systems. The available rainfall data of 60 years was segmented into six decadal rainfall sets and used for continuous simulation of 10 years rainwater harvesting.

Prevalent residential buildings in Dhaka city are built on 2.5-5.0 katha plots and based on (Karim et al., 2015), has $60-70 \%$ the plot area as available catchment area for rainwater collection. For the purpose of this study, two different sizes of flat/ apartment were considered, large apartments on 5.0 katha plots with $200 \mathrm{~m}^{2}$ catchment area and daily water consumption of 200 lpcd (liters per capita per day), and a smaller size apartment built on 2.5 katha plot with catchment area $110 \mathrm{~m}^{2}$ and daily water consumption of $120 \mathrm{lpcd}$. Population of 50 for the larger apartments and population of 30 for smaller flats were assumed as done by (Karim et al., 2015). The daily water consumption pattern was based on flat sized based classification guideline provided by Bangladesh National Building Code (BNBC, 2015). Also, roof runoff coefficient was considered as 0.95 as recommended by BNBC guidelines (BNBC, 2015).

\section{Results and Discussion:-}

The six decadal annual average rainfall data was used to observe the average rainfall volume change from decade to decade as percentage change using the decade 1955-1964 as the baseline in Figure 2. A clear pattern of initially increasing rainfall for the next two decades during 1965-1975 and 1976-1985 is observed at $+1.55 \%$ and at $+10.88 \%$ respectively. Then for the next two decades, a gradually decreasing trend is observed at $+8.22 \%$ and $+7.66 \%$ for the decades 1986-1995 and 1996-2005. The decreasing trend continues for the next decade 2006-2015 but this time the change appears to be quite drastic, at $-5.09 \%$ compare to the baseline of 1955-1964. The change appears to be even more drastic if compared with the immediate previous decade $1996-2005$, at $-11.85 \%$. That is a significant decrease in rainfall and might possibly affect RWH systems considerably.

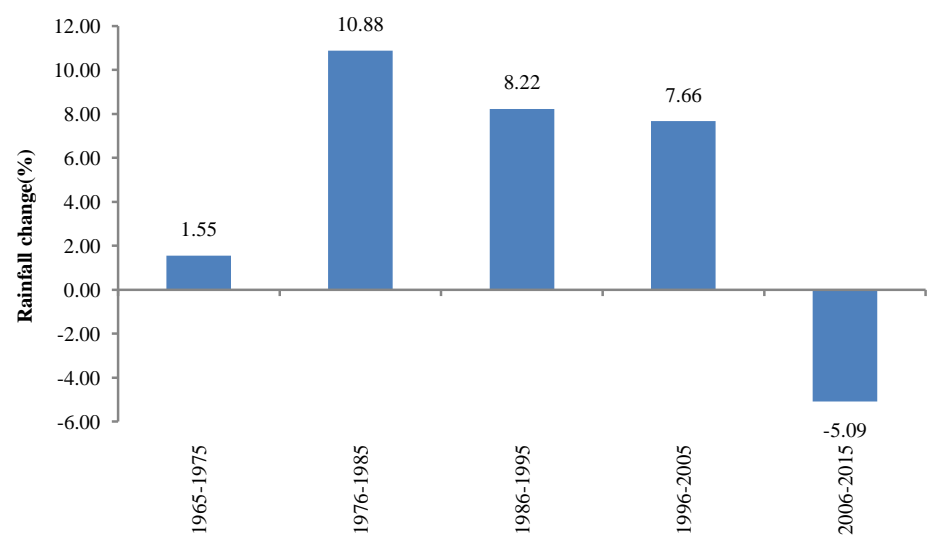

Figure 2:-Decadal rainfall change (\%) from baseline values of 1955-1964

\section{Frequency Analysis}

The frequency analysis for the six decadal rainfall data was carried out and probability curve was developed based on the rainfall event ranking sorted as described previously. 
As observed from the graphs, the probability curves for rainfall events have shifted to the right slightly for the decade 1965-1975 compared to 1955-1964. This indicates a higher overall frequency of larger rainfall events. The shift of the curve to the right for the decade 1976-1985 and 1986-1995 compared to the baseline 1955-1964 decade is even more prominent and therefore indicates an even greater frequency of larger rainfall events. The rainfall depths for different exceedance probabilities $(10 \%, 50 \%$ and 90\%) were calculated as can be found in table 2 . Notable change occurred for $10^{\text {th }}$ percentile exceedance probability for the decades 1976-1985, 1996-2005, 20062015, from $41 \mathrm{~mm}$ to $46 \mathrm{~mm}$ (12.2\%), from $47 \mathrm{~mm}$ to $44.5 \mathrm{~mm}(-5.3 \%)$ and from $44.5 \mathrm{~mm}$ to $40.1 \mathrm{~mm}(-9.9 \%)$ respectively. Dry day duration slightly decreased for $10^{\text {th }}$ and $25^{\text {th }}$ percentile probability for all decades after the first decade in consideration, 1955-1964. Also, the number of average wet days per year as shown in table 1 is also a good indicator of the variability of the reduction in dry days and increase in wet days since the 1955-1964. For the sake of brevity, the probability curves were omitted.

\begin{tabular}{|c|c|c|c|c|c|c|}
\hline \multirow{2}{*}{ Decade } & $\begin{array}{c}\text { Rainfall } \\
(\mathrm{mm})\end{array}$ & $\begin{array}{c}\text { Rainfall } \\
(\mathrm{mm})\end{array}$ & $\begin{array}{c}\text { Rainfall } \\
(\mathrm{mm})\end{array}$ & $\begin{array}{c}\text { Dry } \\
\text { dauration(d) }\end{array}$ & $\begin{array}{c}\text { Dry } \\
\text { dauration(d) }\end{array}$ & $\begin{array}{c}\text { Dry } \\
\text { dauration(d) }\end{array}$ \\
\cline { 2 - 7 } & \multicolumn{7}{|c|}{ Exceedance Probability (\%) } \\
\cline { 2 - 7 } & $10 \%$ & $50 \%$ & $90 \%$ & $10 \%$ & $25 \%$ & $50 \%$ \\
\hline $1955-1964$ & 41 & 8 & 1 & 9 & 4 & 1 \\
\hline $1965-1975$ & 41 & 8 & 1 & 8 & 3 & 1 \\
\hline $1976-1985$ & 46 & 9 & 1 & 8.5 & 3 & 1 \\
\hline $1986-1995$ & 47 & 9 & 1 & 8 & 3 & 1 \\
\hline $1996-2005$ & 44.5 & 8 & 1 & 7 & 3 & 1 \\
\hline $2006-2015$ & 40.1 & 7.2 & 0.5 & 8 & 3 & 1 \\
\hline
\end{tabular}

Table 2:-Exceedance probability of rainfall events and dry day duration for the evaluated six decades

Simulation results and RWH system performance analysis Reliability analysis
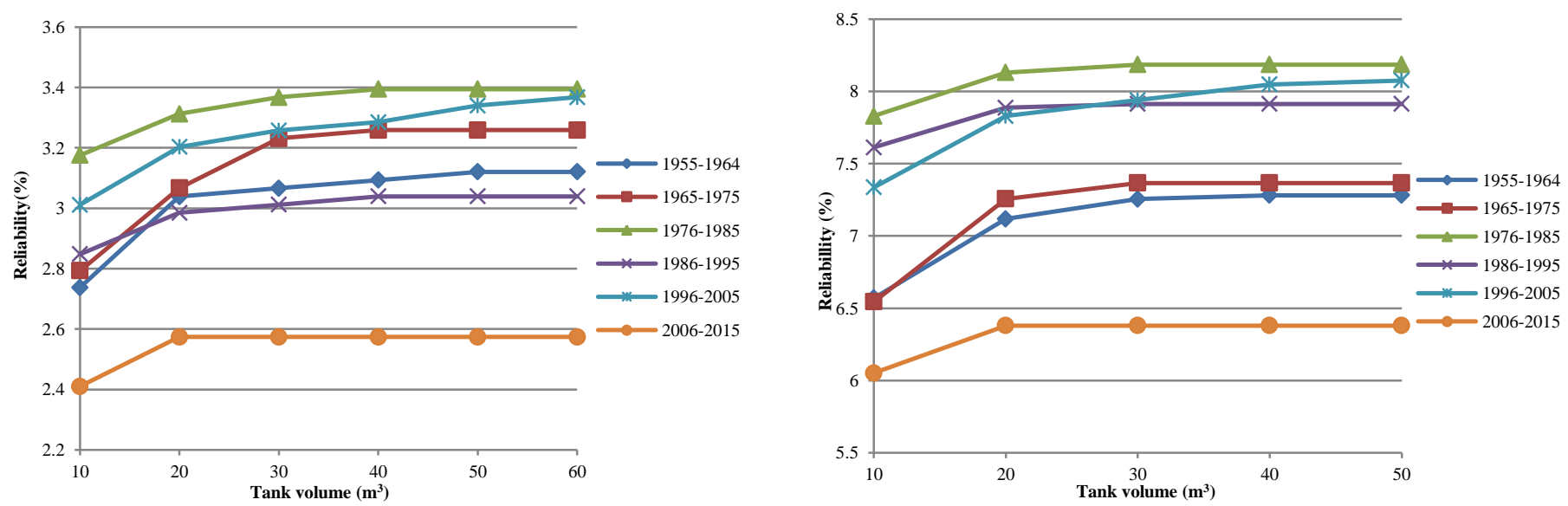

Figure 3:-Reliability of RWH systems for different storage volumes for six different decades for catchment area (a) $200 \mathrm{~m}^{2}$ on the left and (b) $110 \mathrm{~m}^{2}$ on the right

Figure 3 represents the relationship of reliability with storage tank volume for two different catchment areas, populations and water demand scenarios. Reliability is considerably low even in the best possible scenario i.e. slightly above $8 \%$ for catchment area $110 \mathrm{~m}^{2}$ and water demand of $120 \mathrm{lpcd}$ for 30 people. There is noticeable change in reliability for catchment area and water demand scenario for different decadal datasets. For case (a), time period 1976-1985 had the highest reliability at nearly $3.4 \%$ for tank size $40 \mathrm{~m}^{3}$. However, in decade $2006-2015$, reliability falls to $2.4 \%$ and has no impact for storage volumes provided above $20 \mathrm{~m}^{3}$. For case (b), highest reliability is again achieved in the decade $1976-1985$ at $8.2 \%$ at $30 \mathrm{~m}^{3}$ storage volume. Once again, lowest reliability was achieved in the decade $2006-2015$ at $6.4 \%$ at $20 \mathrm{~m}^{3}$ storage volume. 

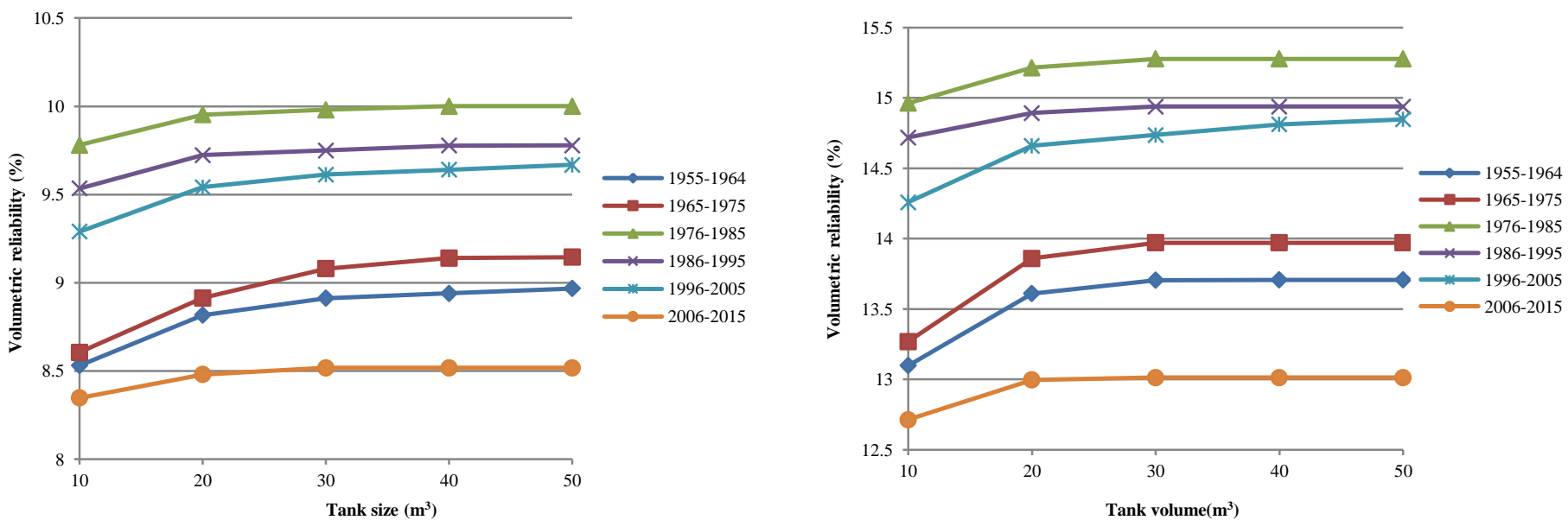

Figure 4:-Volumetric Reliability of RWH systems for different storage volumes for six different decades for catchment area (a) $200 \mathrm{~m}^{2}$ on the left and (b) $110 \mathrm{~m}^{2}$ on the right

Figure 4 represents the relationship of volumetric reliability with storage tank volume for two different catchment areas, populations and water demand scenarios. Although volumetric reliability fares comparatively better than reliability, it is shows that RWH cannot be relied heavily on as a primary source of water. The best case scenario occurs again, in the smaller catchment area with lower water demand i.e. $110 \mathrm{~m}^{2}$ with $120 \mathrm{lpcd}$ demand for 30 persons at slightly below $15.5 \%$ for tank volume $20 \mathrm{~m}^{3}$ during the decade 1976-1985. During decade 2006-2015, this falls to $13 \%$ at tank volume $20 \mathrm{~m}^{3}$. For the $200 \mathrm{~m}^{2}$ catchment area with $200 \mathrm{lpcd}$ water demand with 50 people scenario, the volumetric reliability is highest in the decade 1976-1985 at slightly below 10\% maxing out at tank volume $30 \mathrm{~m}^{3}$. Once again, the decade 2006-2015 generates the lowest volumetric reliability of $8.5 \%$ for tank volume $20 \mathrm{~m}^{3}$. It may be observed that the change in either reliability or volumetric reliability has not changed by a large margin. However, considerable reduction in both cases in the last decade evaluated in noticeable.

\section{Water savings potential}
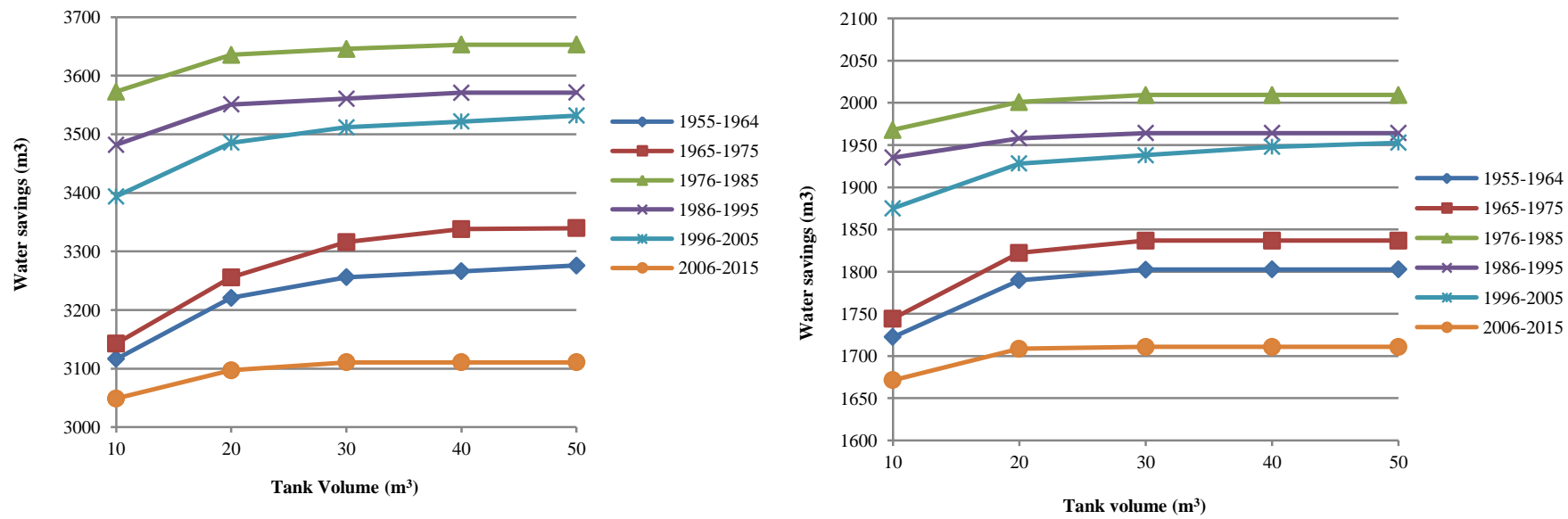

Figure 5:-Water savings of RWH systems for different storage volumes for six different decades for catchment area (a) $200 \mathrm{~m}^{2}$ on the left and (b) $110 \mathrm{~m}^{2}$ on the right

Figure 5 above illustrates the water savings potential for different tank volumes for the two different water demand scenarios for the different catchment area during the six decade in consideration. It should be noted that while the high demand, large catchment area option showed overall lower reliability than the smaller catchment, lower demand, the high demand, larger catchment shows considerably higher water savings. The best scenario for water savings for the larger catchment occurs at around $3650 \mathrm{~m}^{3}$ for tank size $30 \mathrm{~m}^{3}$. At the same tank volume, the smaller 
catchment area has water savings potential slightly above $2000 \mathrm{~m}^{3}$. Other noticeable factors include the considerable change of water savings amount from decade to decade.

\begin{tabular}{|c|c|r|r|r|r|r|}
\hline $\begin{array}{c}\text { Tank size } \\
\left(\mathrm{m}^{3}\right)\end{array}$ & $1955-1964$ & $1965-1975$ & $1976-1985$ & $1986-1995$ & $1996-2005$ & \multicolumn{1}{c|}{$2006-2015$} \\
\hline 10 & 3116.49 & 3142.72 & 3572.66 & 3481.9 & 3393.797 & 3048.744 \\
\hline 20 & 3220.7 & 3255.48 & 3635.61 & 3550.82 & 3485.487 & 3097.084 \\
\hline 30 & 3255.94 & 3315.88 & 3645.61 & 3560.82 & 3511.787 & 3110.68 \\
\hline 40 & 3265.94 & 3338.07 & 3653.13 & 3570.82 & 3521.787 & 3110.68 \\
\hline 50 & 3275.94 & 3339.63 & 3653.13 & 3571.05 & 3531.787 & 3110.68 \\
\hline
\end{tabular}

Table 3:-Water savings potential $\left(\mathrm{m}^{3}\right)$ for different tank sizes for the large catchment area high demand scenario
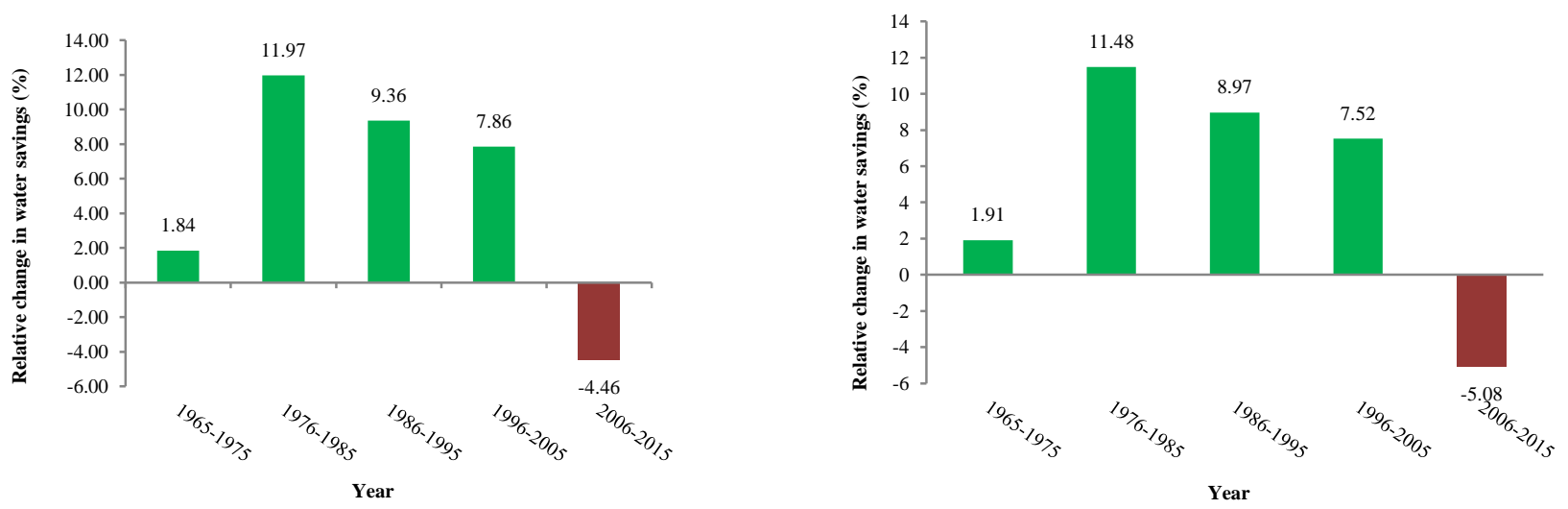

Figure 6:-Relative change in water savings of RWH systems equipped with $30 \mathrm{~m} 3$ storage volume for different storage volumes for five different decades compared to baseline $1955-1964$ for (a) $200 \mathrm{~m}^{2}$ on the left and (b) $110 \mathrm{~m}^{2}$ on the right

Figure 6 is probably the most important one in the context of this study. It illustrates the relative change of water savings made by using RWH during the later decades compared against the baseline time period of 1955-1964. For both catchment area and water demand scenario, the figure paints a similar picture. There is significant rise in the water savings potential up to decade 1976-1985 in both scenarios. However, the water savings potential steadily declines during the next two decades. Finally, during the most recent decade, during 2006-2015, a drastic fall in water savings potential for RWH systems for both scenarios is observed. The decreasing trend in previous two decades and the drastic decrease in the latest decade is possible indication that the overall water saving potential of RWH systems in Dhaka city may take a significant hit due to climate change impacts.

\section{Conclusions:-}

Current sources of water around the globe are under stress and often times being used unsustainably to meet the needs of a rapidly growing population. The impacts of climate change are expected to exacerbate the situation in most cases. As one of the most vulnerable countries against climate change, Bangladesh must find strategies to cope with the apparently doomed situation. RWH, a popular technology adopted in many countries in recent times to deal with water scarcity, is taking roots in Bangladesh as well, especially in the legislative and policy making level. This paper proposes a methodology to assess the impact of climate change on RWH systems in Dhaka City by observing the variation in the historical data. A software was developed to simulate daily water balance model using rainfall depth, catchment area and daily water demand as input to generate reliability, volumetric reliability and water saving efficiency under varying circumstances of rainfall pattern as was present in the historical data.

Exceedance probability curves formed using frequency analysis of rainfall events and dry day duration clearly showed a change in pattern of rainfall. While not very large, noticeable change in reliability and volumetric reliability was observed for both large catchment high demand and smaller catchment low demand scenario for varying rainfall pattern in different decades. The decade 1976-1985 showed highest reliability and volumetric 
reliability of $3.4 \%-8.2 \%$ and $10 \%-15.2 \%$ respectively between the two different demand and catchment area scenarios, while the lowest of those parameters were observed during the recent decade of 2006-2015 to vary at $2.6 \%-6.4 \%$ and $8.5 \%-13 \%$ respectively for the two different scenarios. While not major, the change is noticeable. Considerable amount of change has been observed with respect to water saving potential of RWH systems in both scenarios. There is a clear pattern of consistently decreasing water savings potential of RWH systems which took quite a drastic turn during the last decade, falling by $4.5 \%$ and $5.1 \%$ in the two catchment area/ water demand scenarios compared to the baseline decade 1955-1964 and even more drastic if relative change is considered with respect to the immediate previous decade, 1996-2005.

The results of this study indicate that there is a possibility that impact of climate change will negatively affect RWH systems in Dhaka city. The limitations of the study include the data availability which is rather limited for a work of this scope. Historical data was used to ascertain the trend of change in rainfall due to climate change. This data can be considered to be relatively accurate. Future rainfall data from climate projection models can be contain incredible amount of uncertainties in their assumption including but not exclusive to uncertainty in GCMs, their assumption regarding future greenhouse gases emission scenarios, scenario initialization parameters, and uncertainty in downscaling. However, this type of assessment should not only be restricted to historically available data, rather future projected data from climate models should also be used in these type of assessment to evaluate the RWH systems and possibly gain other perspectives and insights unavailable in the use of historical data.

\section{Reference:-}

1. Alamdari, N., Sample, D. J., Liu, J., \& Ross, A. (2018). Assessing climate change impacts on the reliability of rainwater harvesting systems. Resources, Conservation and Recycling, 132, 178-189.

2. Banu, Z., Chowdhury, M. S. A., Hossain, M. D., \&Nakagami, K. I. (2013). Contamination and ecological risk assessment of heavy metal in the sediment of Turag River, Bangladesh: An index analysis approach. Journal of water Resource and Protection, 5(02), 239.

3. Bashar, M. Z. I., Karim, M. R., \&Imteaz, M. A. (2018). Reliability and economic analysis of urban rainwater harvesting: A comparative study within six major cities of Bangladesh. Resources, Conservation and Recycling, 133, 146-154.

4. BNBC (2015). Bangladesh National Building Code. Housing and Building Research Institute. Ministry of Housing and Public Works, Bangladesh.

5. Burns, M. J., Fletcher, T. D., Duncan, H. P., Hatt, B. E., Ladson, A. R., \& Walsh, C. J. (2015). The performance of rainwater tanks for stormwater retention and water supply at the household scale: An empirical study. Hydrological Processes, 29(1), 152-160.

6. DeSA, U. N. (2019). World Urbanization Prospects: The 2018 Revision.Population division of the department of economic and social affairs of the United Nations Secretariat, New York. Retrieved on $2^{\text {nd }}$ September, 2019 from https://population.un.org/wup/Publications/Files/WUP2018-Report.pdf

7. DWASA (2019) Annual Report 2017-2018. Dhaka Water Supply and Sewerage Authority, Dhaka, Bangladesh. Retrieved on $4^{\text {th }}$ September, 2019 from http://dwasa.org.bd/wp-content/uploads/2019/07/Annual-Report-201718.pdf

8. Fisher-Jeffes, L. N. (2015). The viability of rainwater and stormwater harvesting in the residential areas of the Liesbeek River Catchment, Cape Town (Doctoral dissertation, University of Cape Town).

9. Geraldi, M. S., \&Ghisi, E. (2017). Influence of the length of rainfall time series on rainwater harvesting systems: A case study in Berlin. Resources, Conservation and Recycling, 125, 169-180.

10. Godskesen, B., Hauschild, M., Rygaard, M., Zambrano, K., \&Albrechtsen, H. J. (2013). Life-cycle and freshwater withdrawal impact assessment of water supply technologies. Water research, 47(7), 2363-2374.

11. Gould, J., Qiang, Z., \&Yuanhong, L. (2014). Using every last drop: rainwater harvesting and utilization in Gansu Province, China. Waterlines, 33(2), 107-119.

12. Guo, Y., \&Baetz, B. W. (2007). Sizing of rainwater storage units for green building applications. Journal of Hydrologic Engineering, 12(2), 197-205.

13. Han, M. Y., \&Mun, J. S. (2011). Operational data of the Star City rainwater harvesting system and its role as a climate change adaptation and a social influence. Water Science and Technology, 63(12), 2796-2801.

14. Karim, M. R., Bashar, M. Z. I., \&Imteaz, M. A. (2015). Reliability and economic analysis of urban rainwater harvesting in a megacity in Bangladesh. Resources, Conservation and Recycling, 104, 61-67.

15. Khan, T. A. (2013). Dhaka Water Supply and Sewerage Authority: Performance and Challenges. Web report. Retrieved on $5^{\text {th }}$ September, 2019 from http://dwasa.org.bd/wp-content/uploads/2015/10/Dhaka-WASA-Articlefor-BOOK.pdf 
16. Khastagir, A., \&Jayasuriya, N. (2010). Optimal sizing of rain water tanks for domestic water conservation. Journal of Hydrology, 381(3-4), 181-188.

17. Kus, B., Kandasamy, J., Vigneswaran, S., \&Shon, H. K. (2010). Analysis of first flush to improve the water quality in rainwater tanks. Water science and technology, 61(2), 421-428.

18. Martinson, B., \& Thomas, T. (2005). Quantifying the first flush phenomenon. In 12th International Rainwater Catchment Systems Conference.

19. Mati, B., De Bock, T., Malesu, M., Khaka, E., Oduor, A., Meshack, M., \&Oduor, V. (2006). Mapping the potential of rainwater harvesting technologies in Africa. A GIS overview on development domains for the continent and ten selected countries. Technical Manual, 6, 126.

20. Micklin, P., \&Aladin, N. V. (2008). Reclaiming the Aral Sea. Scientific American, 298(4), 64-71.

21. Rahman, A., Keane, J., \&Imteaz, M. A. (2012). Rainwater harvesting in Greater Sydney: Water savings, reliability and economic benefits. Resources, Conservation and Recycling, 61, 16-21.

22. RajUK, P. (2015). Draft Dhaka Structure Plan Report 2016-2035(Full Volume). Capital Development Authority, Government of Bangladesh. Retrieved on $3^{\text {rd }}$ September, 2019 from http://rajukdhaka.gov.bd/rajuk/image/slideshow/1.\%20Draft\%20Dhaka\%20Structure\%20Plan\%20Report\%202 016-2035(Full\%20\%20Volume).pdf

23. Richey, A. S., Thomas, B. F., Lo, M. H., Reager, J. T., Famiglietti, J. S., Voss, K., ...\&Rodell, M. (2015). Quantifying renewable groundwater stress with GRACE. Water resources research, 51(7), 5217-5238.

24. Ringelstein, O. (2015). Now we can shower with Rain Water. GWF Wasser-Abwasser, 156, 58-61.

25. Stocker, T. (Ed.). (2014). Climate change 2013: the physical science basis: Working Group I contribution to the Fifth assessment report of the Intergovernmental Panel on Climate Change. Cambridge University Press.

26. Umapathi, S., Chong, M. N., \& Sharma, A. (2012). Investigation and monitoring of twenty homes to understand mains water savings from mandated rainwater tanks in South East Queensland. Urban Water Security Research Alliance.

27. WMO, (1989). Calculation of Monthly and Annual 30-years Standard Normal. World Meteorological Organization, Geneva (WMO, technical document, n. 341; WCDP, n. 10).

28. Zaman, A. M. (2017, August 7). Dhaka and her rivers. The Daily Star. Retrieved on 4th September, 2019 from https://www.thedailystar.net/opinion/environment/dhaka-and-her-rivers-1444537. 